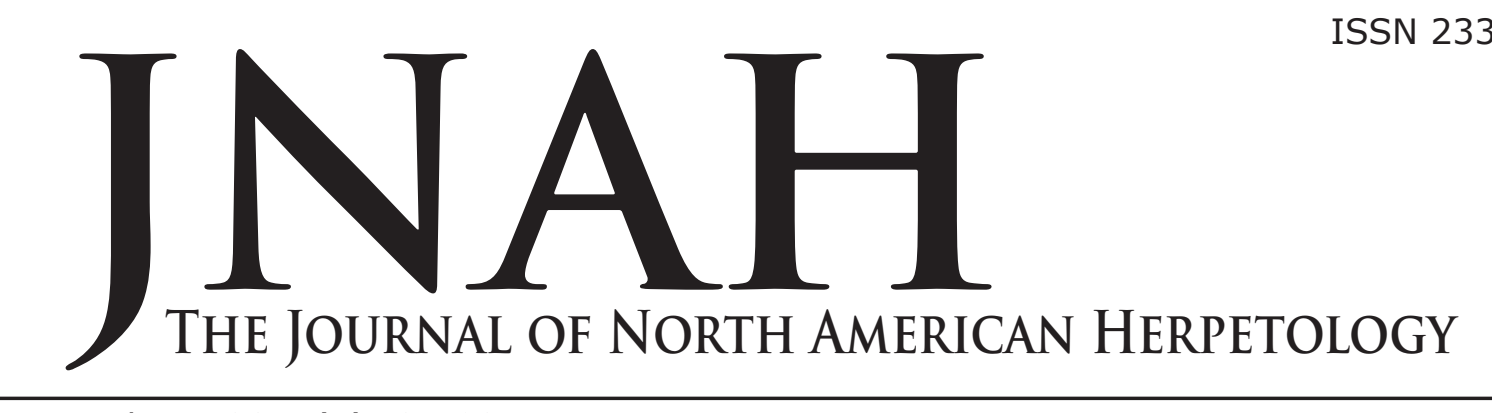

Volume 2014(1): 87-92

2 July 2014

jnah.cnah.org

\title{
EVIDENCE OF COMMUNAL OVIPOSITION AND NEST ABANDONMENT IN THE NORTHERN TWO-LINED SALAMANDER (EURYCEA BISLINEATA, (GREEN, 1818)) IN NORTHEASTERN CONNECTICUT
}

\author{
TAYLOR F. FERGUSON ${ }^{1}$, ELIZABETH K. TIMPE ${ }^{1}$, AND ELIZABETH L. JOCKUSCH ${ }^{1 *}$ \\ ${ }^{1}$ Department of Ecology \& Evolutionary Biology, University of Connecticut, 75 N. Eagleville Rd., U-3043, \\ Storrs, CT 06269-3043, USA \\ * corresponding author contact information: elizabeth.jockusch@uconn.edu (e-mail), 860-486-4452 \\ (phone); 860-486-6364 (FAX)
}

\begin{abstract}
Most plethodontid salamanders oviposit their eggs in an individual nest and attend the clutch until hatching. Here, we describe aspects of the reproduction of Eurycea bislineata (Northern Two-lined Salamander) from three field sites in northeastern Connecticut that contrast with the typical plethodontid reproductive behavior. Rocks used as oviposition sites contained up to 296 eggs, with an average of more than 100 . These numbers exceed the maximum ovarian egg counts for this species, indicating that communal oviposition is common. The lack of correlation between rock size and number of eggs, as well as the lack of discrete clutches when eggs are laid in large clusters, suggests that communal oviposition may be caused by something other than nest site limitation. Additionally, the rate of maternal attendance at nests was low. Thus, communal oviposition with high rates of nest abandonment is the dominant reproductive strategy in E. bislineata at these sites.
\end{abstract}

\section{INTRODUCTION}

Species that occupy broad geographic ranges provide an opportunity to study how variation in ecological parameters can cause variation in life history characteristics. Important ecological parameters include photoperiod, temperature, precipitation, resource distribution, and predator abundance (Morrison and Hero 2003). Reports of variation in life history are necessary in order to better understand the factors that drive intra- and interspecific variation. In amphibians, some life history traits, such as breeding season and length, are evolutionarily labile even within species (e.g., Howard and Wallace 1985; Jockusch and Mahoney 1997), while other traits remain fixed over long evolutionary periods. Ancestrally, salamanders in the family Plethodontidae were characterized by a life cycle in which females oviposited their eggs as a single clutch and then guarded them throughout embryogenesis (Ryan and Bruce 2000). These life history traits appear to be retained by most extant species (Crump 1996; Wells 2007). Egg guarding is regarded as a means of increasing hatching success, with studies of Desmognathus spp. showing that removal of the brooding female almost always results in complete mortality of the clutch (Jaeger and Forester 1993). The female's presence has been hypothesized to protect eggs from desiccation, microbial infection, and predation, and to provide increased aeration to aquatic eggs (Wells 2007).
Absence of maternal care is rare in plethodontids, but has been noted for several taxa, including multiple species in the bolitoglossine genera Batrachoseps and Nototriton (Jockusch and Mahoney 1997). Solitary oviposition is also retained by the majority of plethodontid species, but communal oviposition has evolved multiple times, including in Hemidactylium scutatum (Four-toed Salamander), Batrachoseps, and Nototriton (Jockusch and Mahoney 1997).

The Northern Two-lined Salamander (Eurycea bislineata) has previously been described as exhibiting nesting behaviors typical of plethodontid salamanders: female brooding of eggs until hatching and little sharing of oviposition sites (Bishop 1941; Petranka 1998). Previous studies documenting the nesting ecology of $E$. bislineata have reported relatively small nest sizes, with the mean number of eggs ranging from 15.4 (Bahret 1996) to 34 (Stewart 1956; Table 1). These are below the reported mean ovarian egg complement of 46 (Stewart 1968). These reports come from throughout the range of the species, which extends across northeastern North America, from Labrador and Northern Quebec south to Virginia and west to Ohio. However, in some reports, the maximum egg count far exceeded the expected clutch size: 121 (Stewart 1956), 165 (Bishop 1941; LeGros 2011), 225 (Weber 1928; Table 1). These findings are suggestive of communal oviposition, although it is clearly not 
the predominant strategy as the finding of large nests almost always occurred in isolation and mean clutch sizes reported are much lower. Here, the nesting ecology of $E$. bislineata is reported from three field sites in northeastern Connecticut. In these populations, communal oviposition is the dominant breeding strategy. In addition, we report a relatively low proportion of nests with female attendance.

\section{MATERIALS AND METHODS}

Study site

Nests of $E$. bislineata were observed at three field sites in Tolland County, Connecticut. Two sites were located on the University of Connecticut's Storrs campus (UConn), with one stream located in the UConn Forest (N 41.82544․, W $72.24985^{\circ}$ ) and the other in the Hillside Environmental Education Park (HEEP; N 41.81905, W 72.26990). The third site was located at Gay City State Park in Hebron, CT (N 41.72595, $\left.\mathrm{W} 72.44973^{\circ}\right)$. These sites are separated by $1.8-19.9 \mathrm{~km}$. All sites contained running homogeneous streams or brooks located in mixed deciduous forests (Figure $1 \mathrm{~A}$ ). Much of the streambed was covered in rocks, providing numerous possible nesting substrates. Syntopic species encountered include Desmognathus fuscus (Northern Dusky Salamander), Lithobates clamitans (Green Frog), L. palustris (Pickerel Frog), dragonfly larvae, and crayfish (Cambarus spp.).

\section{Field sampling}

Field work occurred from 25 April - 1 June 2012. Nests were located by turning over rocks along the streambed starting at a fixed point (usually where the stream bisected the marked trail) and moving along the stream. We
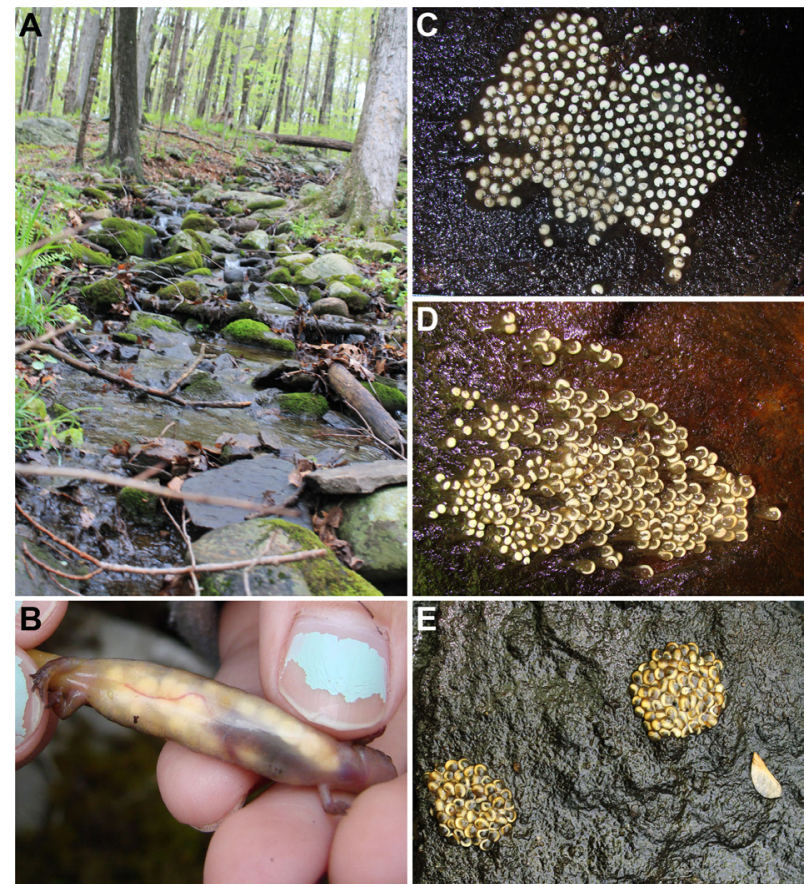

Figure 1: Field observations of reproduction in E. bislineata. A) Stream at the Hillside Environmental Education Park (HEEP) field site showing that the streambed is largely covered in rocks; B) gravid female from HEEP found under a rock that already contained 53 eggs; C) nest containing 296 eggs, all at similar developmental stages; D) nest containing 263 eggs in two different developmental stages; E) rock with two discrete clusters of eggs, containing 55 (left) and 69 (right) eggs. attempted to examine all rocks except those too large or deeply embedded in the substrate to lift. Undersides of rocks were inspected for the presence of eggs. Forty-three nests were found, and 23 nests were collected for developmental observation in the lab. Two nests were monitored in the field for the same purpose. Nests were photographed with a Canon EOS Rebel T3 12.2 MP CMOS Digital SLR camera. The egg count of each nest was determined in the lab using the count feature in the shareware software package Image] (Rasband 2014). For the 25 nests used for developmental observation, the developmental stage of eggs was recorded as were the maximum length and width of the rock. Rock surface area was estimated as the product of these measurements.

In order to locate attending $E$. bislineata females, rocks were lifted carefully so as to minimize the amount of debris and silt clouding the water. In contrast to the behavior of $E$. bislineata that were not attending clutches, those found in association with eggs tended to remain stationary when exposed. If no females were attending the nest then all rocks and vegetation in the surrounding area were searched. Nests were treated as attended if a female was found in the immediate surroundings; this gives a conservative estimate of the rate of nest abandonment.

\section{Statistical analyses}

We used ANOVA to test for differences among sites in the number of eggs found in a nest. Linear regression was used to test for relationships between rock size (surface area or maximum length) and number of eggs. Sever (2005) advised considering any clutch exceeding 50 eggs as deposited by more than a single female. To be conservative, we treated any nest exceeding 60 eggs as communal, while nests with 60 or fewer eggs were treated as belonging to a single female. We used Fisher exact tests to evaluate correlations between communal nesting and female attendance as well as between developmental stage (pre-neurulation vs. later) and female attendance. All statistical tests were conducted in $\mathrm{R}$ v. 2.15.2 (R Development Core Team 2012).

\section{RESULTS}

Between 25 April and 1 June 2012, 43 nests were found. (We define nests as spatially separated clusters of eggs.) 42 rocks were used as oviposition sites; in one instance, two spatially separated clusters of eggs were present on a single rock (Figure $1 \mathrm{E}$ ). One nest was not photographed and thus was left out of the analyses because egg count could not be determined. Mean nest size
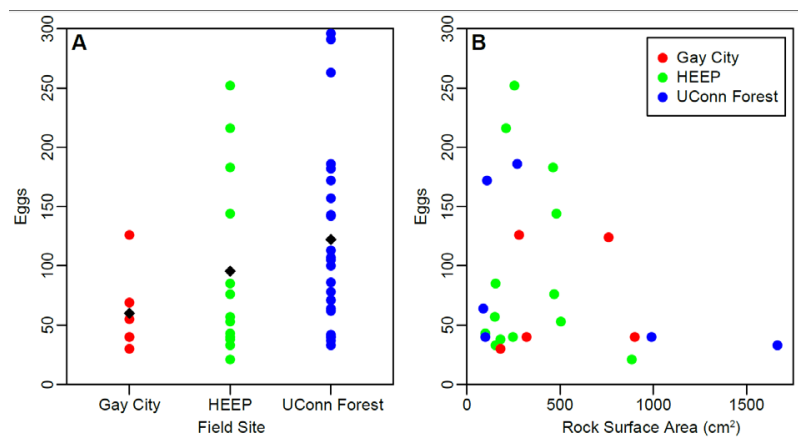

Figure 2: A) Distribution of nest sizes (number of eggs) at three field sites. Black diamonds indicate average for each site. B) Scatterplot of number of eggs vs. rock surface area. Color indicates site, as shown in the legend. No significant relationship was detected. 
Table 1: Nest sizes and fecundity in E. bislineata and its close relatives.

\begin{tabular}{rlrlll}
\hline \multicolumn{1}{c}{$\mathrm{N}$} & Nest size & & \\
& range & mean & Locality & Source \\
\hline \hline E. bislineata & & & & \\
- & $30-50$ & - & Massachusetts & Wilder 1899 \\
- & $12-36$ & 225 & New York & Wilder 1924 \\
1 & 225 & 25 & Not listed & Weber 1928 \\
19 & $3-41$ & 31 & New York & Noble and Richards 1932 \\
6 & $18-43 ; 68^{\text {b, }} ; 165$ & 34 & New York & Bishop 1941 \\
11 & $6-121$ & 46 & New York & Stewart 1956 \\
- & $19-86$ & 35.7 & New York & Stewart 1968 \\
15 & $22-53$ & 15.4 & New York & Jockusch (unpublished data) \\
11 & $5-28$ & 100.0 & Ontario, Canada & Bahret 1996 \\
2 & $35-165$ & 105.0 & Connecticut & LeGros 2011 \\
43 & $21-296$ & & & this study
\end{tabular}

\section{E. cirrigera}

\begin{tabular}{|c|c|c|c|c|}
\hline 8 & $1-34$ & 20 & North Carolina & Noble and Richards $1932^{a}$ \\
\hline 2 & $42-45$ & 43.5 & Virginia & Richmond 1945 \\
\hline 102 & $22-95$ & $50^{d}$ & Ohio & Wood and Duellman 1951 \\
\hline 29 & $18-96 ; 134$; $180 ; 257$ & 52.3 & Virginia & Wood and McCutcheon 1954 \\
\hline 41 & $29-115$ & 71.5 & Virginia & Wood and McCutcheon 1954 \\
\hline 1 & 36 & 36 & Georgia & Martoff 1955 \\
\hline 1 & 36 & 36 & Ohio & Siebert and Brandon 1960 \\
\hline 7 & $40-59$ & 52 & Alabama/Louisiana & Rose and Bush 1963 \\
\hline - & $15-114$ & 50 & Alabama & Mount 1975 \\
\hline 49 & $15-110$ & 39.4 & Ohio & Baumann and Huels 1982 \\
\hline 7 & - & 53 & Mississippi & Marshall 1996 \\
\hline 405 & $1-117$ & 29.8 & Illinois & Jakubanis et al. 2008 \\
\hline 6 & $36-59$ & 47.2 & West Virginia & Brophy and Pauley 2002 \\
\hline 37 & $10-72$ & 36.0 & Georgia & Guy et al. 2004 \\
\hline 9 & $32-71$ & 55.1 & Tennessee (cave) & Niemiller and Miller 2007 \\
\hline 4 & $29-79$ & 53.0 & Tennessee (surface) & Niemiller and Miller 2007 \\
\hline
\end{tabular}

\section{E. wilderae}

$\begin{array}{rllll}1 & 87 & 87 & \text { North Carolina } & \text { Wood } 1949 \\ 1 & 23 & 23 & \text { North Carolina } & \text { Bruce } 1982 \\ 1 & 20 & 20 & \text { North Carolina } & \text { Sever } 1983 \\ 16 & 28-56 & 40.9 & \text { North Carolina } & \text { Bruce } 1988 \\ 3 & 8-34 & 21.3 & \text { North Carolina } & \text { Ryan } 1995\end{array}$

E. aquatica

\begin{tabular}{|c|c|c|c|c|}
\hline 41 & $31-138$ & 65.9 & Alabama/Georgia & Graham et al. 2010 \\
\hline 7 & $60-96$ & 80 & - & Rose and Bush 1963 \\
\hline \multicolumn{5}{|l|}{ E. junaluska } \\
\hline 4 & $30-49$ & 37.5 & North Carolina & Bruce 1982 \\
\hline 10 & $41-68$ & 51.0 & Tennessee/North Carolina & Sever 1983 \\
\hline 1 & 40 & 40 & North Carolina & Ryan 1998 \\
\hline
\end{tabular}

aShaded rows indicate data from ovarian counts or, in two cases (Jockusch unpublished and Noble and Richards 1932), hormonally induced oviposition in the lab. Jockusch added enlarged ova that were visible through the body wall after oviposition to her totals. Noble and Richards noted that most females oviposited completely, and the others retained only a few eggs.

${ }^{\mathrm{b} C o n t a i n e d ~ e g g s ~ a t ~ t w o ~ d e v e l o p m e n t a l ~ s t a g e s ~}$

cNumbers listed after range were not included in reported mean dMedian, instead of mean

was $105.0 \pm 76.1$ eggs (range $=21-296$ ) and did not differ significantly across sites (Figure 2A; ANOVA, $F=1.80$, d.f. $=2,39, \mathrm{p}=0.18 ; \overline{\mathrm{x}}=95.5 \pm 77.1, \mathrm{n}=13$ (HEEP); $\overline{\mathrm{x}}=$ $60.0 \pm 35.1, n=6$ (Gay City); $\bar{x}=122.2 \pm 79.7, n=23$ (UConn Forest)). Using the threshold of 60 eggs, $62 \%$ (26 of 42) of nests, containing $85 \%$ of eggs (3769 of 4411 eggs), were communal (Fig. 1C-D). Egg counts in 18 nests exceeded the maximum reported ovum count (86) for E. bislineata (Stewart 1968; Table 1). The mean egg count for nests treated as solitary was $40.1 \pm 9.2$; in three of these, the number of eggs exceeded Sever's (2005) recommended cut-off of 50 . The mean egg count for nests treated as communal was $145.0 \pm 71.4$. In a few cases, it was clear that eggs in a single nest were in varying developmental stages (Figure 1D). However, most large nests contained eggs that were relatively uniform in developmental stage. No relationship was detected between the size of rocks used as oviposition sites and the number of eggs oviposited on it (Figure 2B; rock surface area: $r^{2}=0.049, p=0.30$; maximum rock axis: 
$\left.r^{2}=0.012, p=0.61\right)$.

Information on female attendance was collected only for those nests used for developmental observation $(n=25)$. Overall, females were found at 11 of 25 nests $(44 \%)$. There were three cases in which two females were found in close association with a single nest (i.e., under the same rock). Of the fourteen females found in association with these nests, three females were very clearly gravid. However, it is unlikely that gravid females produced the eggs of the nest they were found with, as egg counts were over 40 in each nest and the females were highly gravid (Figure $1 \mathrm{~B}$ ). Attendance excluding the gravid females was $32 \%$ ( 8 of 25 nests). There was no association between whether or not a nest was communal and whether or not it was attended (Fisher's exact test, $p=0.66$ ). Females were significantly more likely to be present at nests containing embryos in early developmental stages (Fisher's exact test, $p=0.039$ ). Four of six nests in which embryos had not yet reached neurulation were attended, while only three of 18 later-stage nests were. (One nest was excluded from these analyses because egg count and stage were not recorded.)

\section{DISCUSSION}

\section{Evidence for communal oviposition}

Field data collected from northeastern Connecticut indicate that $E$. bislineata in this region exhibited a communal nesting strategy with surprisingly low frequency of female nest attendance. Based on Sever's (2005) indication that nests with more than 50 eggs are likely the product of more than one female, communal nests were present in all three field sites. The mean and maximum egg counts found in this study were much higher than previously reported numbers for other populations of this species (Table 1 ). Our maximum egg counts are particularly compelling; for example, nest sizes of 263, 291, and 296 greatly exceed the largest ovarian egg count (Table 1) and are most certainly the work of multiple females, possibly five or more. Similarity of developmental stage within a communal nest indicates that all eggs were usually oviposited within a short time frame.

Communal oviposition has been observed in only about $7 \%$ of species within the family Plethodontidae (Doody et al. 2009). Communal nesting has also been recorded in a close relative of E. bislineata, E. cirrigera (Southern Twolined Salamander), in Illinois, where $8 \%$ of nests had egg counts exceeding the maximum ovarian egg count for this species (Jakubanis et al. 2008). Other plethodontid genera that regularly exhibit communal nesting include Hemidactylium, Nototriton, and Batrachoseps (Jockusch and Mahoney 1997). Nototriton and Batrachoseps are both direct developers that oviposit terrestrially. Although $H$. scutatum retains the ancestral biphasic life cycle, it also oviposits terrestrially. It is the only plethodontid species in which communal nesting has been studied. It is known to exhibit both solitary and joint nesting in a single population, with the latter comprising $19-52 \%$ of all nests (Harris and Gill 1980; Harris et al. 1995).

Many hypotheses have been proposed to explain the evolution of communal nesting. These can generally be divided into two categories. One category posits adaptive explanations and the other posits a "by-product" mechanism wherein the behavior is a secondary outcome of some other coincidental factor causing the aggregation of nesting females (Doody et al. 2009). Hypothesized causes of communal nesting include saturated habitat, aggressive usurpation, intraspecific brood parasitism, multiple defenders, predation dilution, and kin selection (summarized in Harris et al. 1995). There is a growing body of evidence supporting adaptive explanations over 'by-product' hypotheses, such as saturated habitat, in diverse taxa (Doody et al. 2009).

Before considering adaptive explanations for communal oviposition, the by-product hypothesis of habitat saturation should be considered (Doody et al. 2009). In an experimental setting, females in both high and low density populations chose to oviposit communally at similar frequencies, thus refuting habitat saturation as a viable explanation in H. scutatum (Harris et al. 1995). By contrast, oviposition site limitation has been suggested for several populations of E. cirrigera. Baumann and Huels (1982) found a positive correlation between number of eggs and rock size, as a result of multiple, separated nests occurring more frequently on larger rocks. Similarly, in an Illinois population of $E$. cirrigera, rocks with a larger maximum dimension were more likely to have multiple, spatially separated nests (Jakubanis et al. 2008), although no correlation between number of eggs and rock surface area was found. Finally, artificial substrates were used for oviposition in one of two Georgia populations in which they were provided, also suggesting that oviposition substrates were limited (Guy et al. 2004).

It does not appear that there is oviposition site-limitation in our study population of $E$. bislineata. One prediction of the habitat saturation hypothesis is that larger rocks will have more eggs. This prediction was not supported using either surface area or maximum length as the measure of size. Additionally, even when the eggs on a large rock were oviposited by multiple females, they tended to be tightly clustered rather than placed in discrete clutches, as is often observed when E. cirrigera share an oviposition substrate (Baumann and Huels 1982). Another piece of evidence against the habitat saturation hypothesis is that eggs on a single rock appeared to be more similar in stage than eggs in the entire population. However, further work is needed to test this pattern. If habitat saturation were the cause of communal oviposition, then clutches oviposited together would be predicted to be more divergent in stage. Finally, although we did not quantify the proportion of rocks used for oviposition, only a small proportion of the available rocks were used, and many unused rocks appeared similar to those used for oviposition. Thus, our data point toward an adaptive explanation for communal oviposition in $E$. bislineata in northeastern Connecticut. Nonetheless, it is difficult to completely rule out the habitat saturation hypothesis. It might be difficult to quantify which aspects of a nest site make it of higher quality than others for an organism. Though nest sites may seem in apparent abundance, those of the highest quality might actually be saturated.

\section{Female nest attendance}

For plethodontid salamanders, maternal attendance is usually the rule, with few exceptions (Jockusch and Mahoney 1997). Our data indicate that female parental care in the form of brooding behavior is largely absent in our study populations of $E$. bislineata. We found that a high proportion of nests were unattended, with attending females present at only $17 \%$ of nests in which eggs had reached neurulation (compared to $67 \%$ of nests in which eggs were at an earlier developmental stage). This suggests that the typical pattern is for a female to remain with her clutch briefly before abandoning it. This underlines that there are costs associated with parental 
care behavior. Providing care to eggs may be energetically expensive, reduce investment in future offspring, and incur physical risk to the parent if engaging in defensive behavior (Wells 2007). An experimental study in Plethodon cinereus (Red-backed Salamander) found that females who engaged in brooding behavior produced smaller eggs in subsequent seasons than those who did not brood (Yurewicz and Wilbur 2004).

Joint nests in $H$. scutatum usually have only one brooder, suggesting the abandonment of at least one other female (Harris et al. 1995). Nest abandonment in our study populations of $E$. bislineata may represent another step in the continuum where all females of a communal nest abandon, perhaps because the costs of attendance outweigh the benefits due to the predator dilution effect. Further, a few of the nests that were obviously communal in $E$. bislineata did have a single female brooder. Additional study is needed to determine if a single female at a communal nest represents the first or last ovipositor, which would provide more insight into the reason for abandonment by one or multiple females.

In both $E$. bislineata and $H$. scutatum, communal oviposition either precedes or originates concomitantly with nest abandonment. By contrast, Jockusch and Mahoney (1997) found that loss of female attendance likely preceded the evolution of communal nesting in Batrachoseps and Nototriton, suggesting that there are multiple evolutionary paths to the evolution of unattended communal nests in plethodontids. The frequent co-occurrence of these two rare traits, combined with evidence for multiple routes to the same outcome, suggests that communal oviposition may lower the benefits of providing maternal care, while nest abandonment may increase the benefit of communal oviposition.

There is a trend for longer embryonic periods in salamanders that live in flowing aquatic environments compared to other aquatic habitats; this naturally increases the predation risk on clutches. Nussbaum (1985) proposed that longer embryonic period selected not only for hidden nest sites but also for the evolution of maternal attendance in stream-dwelling species. This is exemplified by his summary of parental care in aquatic-nesting salamanders: only three lentic-nesters exhibit parental care, and the behavior is largely confined to lotic-nesters in the family Plethodontidae, with $E$. bislineata included (Nussbaum 1985). It seems that a lack of parental care in this species has only previously been reported in the literature when the substrate or habitat of egg deposition was unusual. Wood (1953) found an egg mass attached to a pile of dead leaves with no female present, though this may be attributed to the dimensional complexity of the oviposition site, allowing females to escape detection. Bahret (1996) found nests of $E$. bislineata in a lake at a mean depth of $11.3 \mathrm{~m}$, also without attendant females. It should be noted that besides these unusual cases, most natural history reports of $E$. bislineata lack data on female nest attendance. One explanation for this lack is that it is widely accepted that $E$. bislineata females provide parental care (Bishop 1941; Petranka 1998) and thus it becomes unnecessary to report. Alternatively, it may be that females are often not observed, but this has not been reported, perhaps because of uncertainty about whether a female fled. Without additional data on the presence or absence of females at nests, it remains largely unknown whether $E$. bislineata exhibits consistent maternal care behavior throughout most of its range. In $E$. cirrigera, female attendance is generally reported (e.g., Richmond 1945; Baumann and Huels
1982; Marshall 1996; Pauley and Watson 2005), but one study found low rates ranging from $0-50 \%$ depending on year and study population (Jakubanis et al. 2008). Other areas where low rates of nest attendance have been reported for E. cirrigera are West Virginia (Brophy and Pauley 2002) and cave sites in Tennessee (Niemiller and Miller 2007).

\section{Geographic variation in reproductive biology}

Because $E$. bislineata is a species that occupies a broad geographic range, it offers the opportunity to study how changing ecological parameters affect important life history traits. Our study documented the nesting ecology of $E$. bislineata in northeastern Connecticut and has provided preliminary evidence of variation in nesting strategy and parental care behavior in this species. Though communal oviposition in $E$. bislineata is not a novel observation (Table 1), the predominance of joint nesting in a single population has not been observed elsewhere. It is possible that some ecological factor in our study region selects for communal oviposition. Further, either the same or different factors, including communal oviposition itself, may be largely responsible for female abandonment of eggs at some point during the embryonic period. These factors may include increased predation levels, resource distribution, competition with syntopic species, changes in population density, changes in embryonic development period, or some combination of these factors. Additional study is needed to determine what factors have led to communal oviposition and nest abandonment by $E$. bislineata in northeastern Connecticut and the degree to which this life history strategy is found in other regions.

\section{ACKNOWLEDGMENTS}

We would like to thank the University of Connecticut Office of Undergraduate Research for funding this research project through a Summer Undergraduate Research Fund award to TFF, as well as members of the Jockusch lab for support and advice during the execution of this research. Organisms were handled and collected under CT Scientific Collecting Permit \#0913008 to ELJ.

\section{LITERATURE CITED}

Bahret, R. 1996. Ecology of lake dwelling Eurycea bislineata in the Shawangunk Mountains, New York. Journal of Herpetology 30:399-401.

Baumann, W. L., and M. Huels. 1982. Nests of the Twolined Salamander, Eurycea bislineata. Journal of Herpetology 16:81-83.

Bishop, S. C. 1941. Salamanders of New York. New York State Museum Bulletin 324:1-365.

Brophy, T. R., and T. K. Pauley. 2002. Reproduction in West Virginia populations of the Southern Two-lined Salamander (Eurycea cirrigera). The Maryland Naturalist 45:13-22.

Bruce, R. C. 1982. Egg-laying, larval periods and metamorphosis of Eurycea bislineata and E. junaluska at Santeetlah Creek, North Carolina. Copeia 4:755-762.

Bruce, R. C. 1988. An ecological life table for the salamander Eurycea wilderae. Copeia 1988:15-26.

Crump, M. L. 1996. Parental care among the Amphibia. Pp. 109-144 in Rosenblatt, J. T., and C. T. Snowdon (eds.), Parental Care: Evolution, Mechanisms, and Adaptive Significance, Advances in the Study of Behavior, v. 25. Academic Press, San Diego.

Doody, J. S., S. Freedberg, and J. S. Keogh. 2009: Communal egg-laying in reptiles and amphibians: evolu- 
tionary patterns and hypotheses. Quarterly Review of Biology 84:229-252.

Graham, S. P., E. K. Timpe, M. Alcorn, and J. Deitloff. 2010. Notes on the reproduction in the brownback salamander (Eurycea aquatica). IRCF Reptiles \& Amphibians 17:168-172.

Guy, C. J., R. E. Ratajczak Jr., and G. D. Grossman. 2004. Nest-site selection by Southern Two-lined Salamanders (Eurycea cirrigera) in the Georgia Piedmont. Southeastern Naturalist 3:75-88.

Harris, R. N., and D. E. Gill. 1980. Communal nesting, brooding behavior, and embryonic survival of the four-toed salamander, Hemidactylium scutatum. Herpetologica 36:141-144.

Harris, R. N., W. W. Hames, I. T. Knight, C. A. Carreno, and T. J. Vess. 1995. An experimental analysis of joint nesting in the salamander Hemidactylium scutatum (Caudata: Plethodontidae): the effects of population density. Animal Behaviour 50:1309-1316.

Howard, J. H., and R. L. Wallace. 1985. Life history characteristics of populations of the long-toed salamander (Ambystoma macrodactylum) from different altitudes. American Midland Naturalist 113:361-372.

Jaeger, R. B., and D. C. Forester. 1993. Social behavior of plethodontid salamanders. Herpetologica 49:163175.

Jakubanis, J., M. J. Dreslik, and C. A. Phillips. 2008. Nest ecology of Southern Two-lined Salamander (Eurycea cirrigera) in eastern Illinois. Northeastern Naturalist 15:131-140.

Jockusch, E. L., and M. J. Mahoney. 1997. Communal oviposition and lack of parental care in Batrachoseps nigriventris with a discussion of the evolution of breeding behavior in plethodontid salamanders. Copeia 1997:697-705.

LeGros, D. L. 2011. Communal oviposition in the Northern Two-lined Salamander (Eurycea bislineata) in Algonquin Provincial Park, Ontario. Canadian Field-Naturalist 125:363-365.

Marshall, J. L. 1996. Eurycea cirrigera (Southern Twolined Salamander) nest site. Herpetological Review 27:75-76.

Martoff, B. 1955. Observations on the life history and ecology of the amphibians of the Athens area, Georgia. Copeia 1955:166-170.

Morrison, C., and J. Hero. 2003. Geographic variation in life-history characteristics of amphibians: a review. Journal of Animal Ecology 72:270-279.

Mount, R. H. 1975. The Reptiles and Amphibians of Alabama. University of Alabama Press, Tuscaloosa, AL.

Niemiller, M. L., and B. T. Miller. 2007. Subterranean reproduction of the Southern Two-lined Salamander (Eurycea cirrigera) from Short Mountain, Tennessee. Herpetological Conservation and Biology 2:106-112.

Noble, G. K. and L. B. Richards. 1932. Experiments on the egg-laying of salamanders. American Museum Novitates 513:1-25.

Nussbaum, R. A. 1985. The evolution of parental care in salamanders. Miscellaneous Publications, Museum of Zoology, University of Michigan 169:1-50.

Pauley, T. K., and M. B. Watson. 2005. Eurycea cirrigera. Pp. 740-743 in M. Lannoo (ed.), Amphibian Declines: Status of United States Species. University of California Press, Berkeley.

Petranka, J. W. 1998. Salamanders of the United States and Canada. Smithsonian Institution Press, Washington, DC.

R Development Core Team. 2012. R: A language and environment for statistical computing. R Foundation for Statistical Computing, Vienna, Austria. ISBN 3-900051-07-0, URL http://www.R-project.org/.

Rasband, W.S. 2014. ImageJ. U. S. National Institutes of Health, Bethesda, Maryland, USA, http://imagej. nih.gov/ij/.

Richmond, N. D. 1945. Nesting of the Two-lined Salamander on the Coastal Plain. Copeia 1945:170.

Rose, F. L., and F. M. Bush. 1963. A new species of Eurycea (Amphibia: Caudata) from the southeastern United States. Tulane Studies in Zoology 10:121-128.

Ryan, T. J. 1995. The distribution, larval morphology and life history of Eurycea junaluska (Amphibia: Caudata: Plethodontidae). M.S. Thesis, Western Carolina University.

Ryan, T. J. 1998. Larval life history and abundance of a rare salamander, Eurycea junaluska. Journal of Herpetology 32:10-17.

Ryan, T. J., and R. C. Bruce. 2000. Life history evolution and adaptive radiation of hemidactyliine salamanders. Pp. 303-326 in Bruce, R.C., R.G. Jaeger and L.D. Houck (eds.), The Biology of Plethodontid Salamanders. Kluwer Academic/Plenum Publishers, New York.

Sever, D.M. 1983. Observations on the distribution and reproduction of the salamander Eurycea junaluska in Tennessee. Journal of the Tennessee Academy of Science 58:48-50.

Sever, D. M. 2005. Eurycea bislineata. Pp. 735-738 in M. Lannoo (ed.), Amphibian Declines the Conservation Status of the United States Species. University of California Press, Berkeley.

Siebert, D. H., and R. A. Brandon. 1960. The salamanders of southeastern Ohio. Ohio Journal of Science 60:291-303.

Stewart, M. M. 1956. Certain aspects of the natural history and development of the Northern Two-lined Salamander, Eurycea bislineata bislineata (Green), in the Ithaca, New York, region. Ph. D. Dissertation, Cornell University.

Stewart, M. M. 1968. Population dynamics of Eurycea bislineata in New York. Journal of Herpetology 2: $176-177$.

Weber, J. A. 1928. Herpetological observations in the Adirondack Mountains, New York. Copeia 169:106-112.

Wells, K. D. 2007. The Ecology and Behavior of Amphibians. University of Chicago Press: Chicago, Illinois.

Wilder, H. H. 1899. Desmognathus fuscus and Spelerpes bilineatus (Green). American Naturalist 33:231-246.

Wilder, I. W. 1924. The developmental history of Eurycea bislineata in western Mass. Copeia 133:77-80.

Wood, J. T. 1949. Eurycea bislineata wilderae Dunn. Herpetologica 5:61-62.

Wood, J. T. 1953. The nesting of the Two-lined Salamander, Eurycea bislineata, on the Virginia Coastal Plain. Natural History Miscellanea No. 122, Chicago Academy of Sciences, Chicago, Illinois.

Wood, J. T., and W. E. Duellman. 1951. Ovarian egg complements in the salamander Eurycea bislineata rivicola Mittleman. Copeia 1951:181.

Wood, J. T., and H. N. McCutcheon. 1954. Ovarian egg complements and nests of the Two-lined Salamander, Eurycea b. bislineata x cirrigera, from southeastern Virginia. American Midland Naturalist 52:433436.

Yurewicz, K. L., and H. M. Wilbur. 2004. Resource availability and costs of reproduction in the salamander Plethodon cinereus. Copeia 2004:28-36. 